\title{
Mid Term Patency of Different Conduits in Coronary Artery Bypass Surgery
}

\author{
Siddharth Singh ${ }^{1}$ and Amitabh Satsangi ${ }^{2 *}$ \\ ${ }^{1}$ Associate professor, Department of General Surgery, GSVM Medical College and Associated llrh Hospital, India \\ ${ }^{2}$ Post graduate, Department of General Surgery, GSVM Medical College and Associated llrh Hospital, India \\ Received: February 21, 2018; Published: February 28, 2018
}

*Corresponding author: Amitabh Satsangi, Department of General Surgery, GSVM Medical College and Associated llrh Hospital, India, Tel: 918009018081 ; Email: siddharthrs@yahoo.com

\begin{abstract}
Coronary artery disease is narrowing of the coronaries arteries caused by thickening and loss of elasticity of their wall that when sufficiently severe, limits blood flow to the myocardium. There is significant variety of vascular conduits options for coronary artery bypass surgery, however no detailed guidelines on choice of conduits is available till now. Long term patency of conduit is most important factor in determining the morbidity, mortality and quality of life of patient. The purpose of this study is to review the midterm patency of different conduits in coronary artery bypass surgery.
\end{abstract}

Keywords: Coronary artery Disease; Vascular Conduits; Bypass Surgery

Abbreviations: CAD: Coronary Artery Disease; CABG: Coronary Artery Bypass Surgery; LV: Left Ventricular; ACC: American College of Cardiology; AHA: American Heart Association; SPV: Saphenous Vein

\section{Introduction}

Cardiovascular disease accounts for $32 \%$ of all registered death worldwide and coronary artery disease (CAD) is leading cause. Atherosclerosis is most common etiology. In present scenario management of coronary artery disease varies from percutaneous angioplasty to coronary artery bypass surgery (CABG) and CABG has proven to be most effective and best therapy for ischemic heart disease. Two type of conduits i.e. either arteries or vein may be used in CABG as a graft to redirect the blood to ischemic area distal to blockage for symptomatic relive and better survival chances. Common vascular conduits used in CABG are internal thoracic artery, saphenous vein, radial artery, right gastroepiploic artery, ulnar artery. And such wide variety of options has caused controversy and no consensus regarding superiority of graft has been fully established [1-3].

\section{Material and Methods}

Patient admitted in department of cardiovascular and thoracic surgery LPS institute Kanpur with vascular diseases from Dec. 2015 to Oct 2017 were including in the study following procedure. In study 56 people were included. Patient included in the study were cases of coronary artery disease in which CABG was a class I indication. Class I indications for CABG from the American College of Cardiology (ACC) and the American Heart Association (AHA) are as follows

a) Left main coronary artery stenosis $>50 \%$

b) Stenosis of proximal LAD and proximal circumflex $>70 \%$

c) 3-vessel disease in asymptomatic patients or those with mild or stable angina

d) 3-vessel disease with proximal LAD stenosis in patients with poor left ventricular (LV) function

e) 1- or 2-vessel disease and a large area of viable myocardium in high-risk area in patients with stable angina

f) $\quad>70 \%$ proximal LAD stenosis with either ejection fraction $<50 \%$ or demonstrable ischemia on noninvasive testing

Exclusion criteria - Patients having following criteria will not be included in the study:

i. $\quad$ Age $>80$ years;

ii. Small vessel disease

iii. In-operable patients 
iv. Unstable angina or myocardial infarction $<2$ and $<7$ days before surgery, respectively;

v. Previous or concurrent cardiac surgery;

vi. concomitant severe disease;

vii. Inability to repeat coronary angiography due to allergy to contrast agent.

viii. Moribund patients

\section{Definitions of Graft Patency}

Commonly used Anatomic Definitions of Graft Failure are: Total occlusion, greater than $75 \%$ or $50 \%$ stenosis, string-sign and Fitzgibbon A, B, and 0 class (A= patent or stenosis less than $50 \%$, $\mathrm{B}=$ stenosis greater than $50 \%, 0=$ total occlusion). A frequently used definition of a combined end point for a failed graft merges Table 2: Age distribution' these: total occlusion, stenosis greater than $75 \%$ or string-sign. Stenoses in the body of a graft or at either anastomotic site should be considered a failure. Physiological parameters are also used, for example TIMI flow $0=$ no perfusion, $1=$ minimal entry of dye, $2=$ partial and $3=$ normal perfusion $[4,5]$.

\section{Results}

\section{Conduits: (Tables $1 \& 2$ )}

Table 1: Patients' characteristic at the time of admission.

\begin{tabular}{|c|c|}
\hline Number of patients & $\mathbf{5 6}$ \\
\hline Gender distribution & Male(52)/Female(4) \\
\hline Comorbidities & D.M (36\%)/HTN $(41 \%) /$ Both \\
& $(23 \%)$ \\
\hline Number of vessels involved & TVD(36)/DVD(20) \\
\hline
\end{tabular}

\begin{tabular}{|c|c|c|c|c|}
\hline Age Group & $\mathbf{4 0 - 4 9}$ & $\mathbf{5 0 - 5 9}$ & $\mathbf{6 0 - 6 9}$ & $\mathbf{7 0 - 8 0}$ \\
\hline Number Of Subjects & 15 & 21 & 15 & 5 \\
\hline
\end{tabular}

Table 3: Conduits

\begin{tabular}{|c|c|c|}
\hline LIMA & RSVG & RA \\
\hline 56 & 150 & 9 \\
\hline
\end{tabular}

Table 4: Total graft failure.

\begin{tabular}{|c|c|c|}
\hline $\begin{array}{c}\text { Total number of } \\
\text { grafts }\end{array}$ & $\begin{array}{c}\text { Number of graft } \\
\text { failures }\end{array}$ & $\begin{array}{c}\text { Number of graft } \\
\text { patent }\end{array}$ \\
\hline 215 & 26 & 189 \\
\hline
\end{tabular}

Table 5: Early graft failure.

\begin{tabular}{|c|c|c|c|}
\hline Total grafts & RSVG & LIMA & $\begin{array}{c}\text { Total graft } \\
\text { failure }\end{array}$ \\
\hline 215 & 6 & 2 & 8 \\
\hline
\end{tabular}

There were 56 LIMA grafts used, 150 RSVG and 9 RA grafts grafted. Institution LIMA was used mostly to graft the left anterior descending artery (LAD), in this study population all the LIMA grafts were grafted upon the LAD. RSVG and radial artery were used for grafting Right coronary artery, Left circumflex artery, the obtuse marginal branch, diagonal branch, posterior descending artery, ramus intermedius (Table 3 ). Over a period of 2 years patients were followed up and imaging (CT angiography) was done after 1 month and 1 year time period or when the patient was presenting with symptoms suggestive of graft failure. Out of 215 conduits that were grafted a total of 26 conduits were considered as graft failures over a period of 2 years (Tables 4 \& 5). After a follow up of complete 2 years the data that was observed that out of the 54 remaining LIMA, 2 graft failures were recorded. They were recorded after a period of 1 year and thus termed as intermediate graft failure. Out of the 150 RSVG that were grafted, 6 had early graft failure, the remaining 144 grafts were followed up and out of them 12 were found to have failed over the period of 1 year from grafting and labelled as intermediated graft failure. In case of radial artery a total of 9 grafts were grafted out of which 2 grafts failed after a period of 1 year, thus intermediate graft failure of 2 grafts were noted (Table 6).
Table 6: Intermediate graft failure.

\begin{tabular}{|c|c|c|}
\hline Conduits & $\begin{array}{c}\text { Intermediate graft } \\
\text { failure }\end{array}$ & $\begin{array}{c}\text { Total number of } \\
\text { graft }\end{array}$ \\
\hline LIMA & 2 & 54 \\
\hline RSVG & 12 & 144 \\
\hline RA & 2 & 9 \\
\hline
\end{tabular}

\section{Discussion}

CABG is the most common cardiac surgery operation performed worldwide. It has been shown to be the most effective revascularization method for several categories of patients affected by coronary artery disease. Long-term conduit patency is the key factor for the success of the procedure. In our study we used conventional angiography as well as the newer modalities like multislice CT angiography to see the patency of the grafts after fixed intervals after operative intervention had taken place. In our study RSVG showed a patency of $88 \%$ after a period of 1 year. In concordance with various national and international publications it was noticed that Left internal mammary artery has a better patency in comparison saphenous vein graft. The saphenous vein (SPV) is a commonly used conduit for bypass due to the ease of harvest, which can generally be done through minimally invasive procedures, with less scarring and faster recovery. But the failure of vein grafts over the long term remains a significant problem. Compared with the LIMA, the RA seems a better choice in patients at risk for post-operative sternal complications (diabetes, obesity, chronic pulmonary disease). Indeed, harvesting of the RA is extremely safe and well tolerated, even by complex and fragile patients and does not affect sternal vascularisation and healing [6,7].

\section{Conclusion}

There is a significant variety of vascular conduits options for coronary bypass surgery. Adequate graft selection is the most important factor for the success of the intervention. To ensure 
durability, permeability, and bypass function, there must be a morphological similarity between the graft and the coronary artery. Currently, the internal thoracic artery is the standard choice for bypass surgery because of the morphological characteristics of the wall that makes less prone to developing atherosclerosis and hyperplasia. The radial and right gastroepiploic arteries are the following second and third best options, respectively. The Radial artery is most frequently anastomosed with the RCA, the CX, or the PIA, obtaining satisfactory results. Its main advantage is its wide length and thickness, making it a versatile graft and the luminal diameter is similar to the coronary arteries. Its main disadvantage is its propensity to spasm because of its thick muscular tunica media.

\section{References}

1. Loop FD, Lytle BW, Cosgrove DM (1986) Influence of the internalmammary-artery graft on 10-year survival and other cardiac events. $\mathrm{N}$ Engl J Med 314(1): 1-6.

2. Lytle BW, Blackstone EH, Sabik JF (2004) The effect of bilateral internal thoracic artery grafting on survival during 20 postoperative years. Ann Thorac Surg 78(6): 2005-2012.

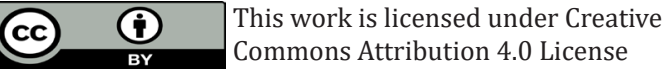

Submission Link: http://biomedres.us/submit-manuscript.php
3. Galbut DL, Kurlansky PA, Traad EA (2012) Bilateral internal thoracic artery grafting improves long-term survival in patients with reduced ejection fraction: a propensity-matched study with 30-year follow-up. J Thorac Cardiovasc Surg 143(4): 844-853.

4. Nwasokwa ON (1995) Coronary artery bypass graft disease. Ann Intern Med 123(7): 528-545.

5. Fitzgibbon GM, Kafka HP, Leach AJ (1996) Coronary bypass graft fate and patient outcome: angiographic follow-up of 5,065 grafts related to survival and reoperation in 1,388 patients during 25 years. J Am Coll Cardiol 128(3): 616-626.

6. Taggart DP, Damico R, Altman DG (2001) Effect of arterial revascularisation on survival: a systematic review of studies comparing bilateral and single internal mammary arteries. Lancet 358(9285): 870875.

7. Stevens LM, Carrier M, Perrault LP (2004) Single versus bilateral internal thoracic artery grafts with concomitant saphenous vein grafts for multivessel coronary artery bypass grafting: effects on mortality and event-free survival. J Thorac Cardiovasc Surg 127(5): 1408-1415.

$\begin{array}{ll}\text { BIOMEDICAL } & \text { Assets of Publishing with us } \\ \text { RESEARCHES } & \text { - Global archiving of articles } \\ \text { - Immediate, unrestricted online access } & \text { - Rigorous Peer Review Process } \\ & \text { - Authors Retain Copyrights } \\ & \end{array}$

